\title{
Presentación de la revista De Arte
}

\author{
Manuel Valdés Valdés \\ Catedrático de Historia del Arte \\ Universidad de León
}

La Junta de Facultad de Filosofía y Letras de la Universidad de León, en sesión celebrada durante el curso 2001-2002, tomó colegiadamente la decisión de suspender la publicación de la revista Estudios Humanísticos (geografía, historia y arte) y, paralelamente, aprobó la creación de dos nuevas revistas, desprovistas del carácter misceláneo de la anterior, abiertas a los trabajos de investigación específicos de historia, por una lado, y de historia del arte por otro.

Terminaba, al menos por el momento, un largo y cambiante proceso editorial que se había iniciado en el Colegio Universitario de León, con la sección de Filosofía y Letras, institución académica creada y financiada durante el curso 1972-1973, hasta su transformación en facultad, por la Caja de Ahorros y Monte de Piedad de León que estaba siendo administrada, desde el punto de vista académico, por la Universidad de Oviedo; un año después se integró en el nuevo centro leonés la sección de Derecho. Las titulaciones del Colegio Universitario se sumaron a las que ya existían en los centros que la Universidad de Oviedo tenía en León, como las facultades de Veterinaria y Biología, y las Escuelas Universitarias de Magisterio, Comercio, Minas y Agrícolas, instituciones universitarias que formaron la base sobre la que se asentó la creación de la Universidad de León a fines del año 1979 (R. D. de 30 de octubre).

Dos años antes, en 1977, los profesores del Colegio Universitario leonés desearon manifestar su respeto, en la mejor tradición universitaria, a una de las personalidades leonesas que había jugado un papel excepcional en la cimentación de la futura Universidad de León, don Emilio Hurtado Llamas, presidente de La Caja, persona que derrochó entusiasmo, trabajo y esfuerzo en unas negociaciones largas, complejas y, a veces, frustrantes. El volumen 3 de las publicaciones del Colegio Universitario, colección creada por el doctor Benito Ruano, fue editado bajo el epígrafe Estudios humanísticos y jurídicos, Homenaje a don Emilio Hurtado Llamas, contenía distintos trabajos de investigación realizados en la institución universitaria que él había apoyado sin reservas. 
Tras la publicación del referido homenaje y la participación colectiva de los investigadores, se estudió la posibilidad de crear una revista con periodicidad anual y el mismo carácter misceláneo, con la finalidad de difundir la producción científica del profesorado del Colegio Universitario. Bajo esta perspectiva, en 1979, salió a la calle el primer número de la revista Estudios Humanísticos, con cuatro secciones: estudios, revista leonesa, notas bibliográficas y crónica informativa. Con ese formato salieron cinco números.

En 1984, con la multiplicación de las especialidades científicas y, consecuentemente, del profesorado, se vio la necesidad de imprimir un giro a la revista en función de una más explícita especialización. Bajo el mismo epígrafe general, Estudios Humanísticos se dividió en dos volúmenes; uno dedicado a materias filológicas y otro a geografía, historia e historia del arte. En el normal desarrollo de las actividades investigadoras de la facultad de Filosofía y Letras vinieron a sumarse, a las dos revistas existentes, Contextos, dedicada especialmente a estudios metodológicos y, en 1991, Polígonos, Revista de geografía que en la actualidad, en su segunda época, es definida como una empresa conjunta, gestionada por los departamentos de geografía de las tres universidades de Castilla y León.

Tras el acuerdo de la facultad del curso académico 2001-2002, referido más arriba, el Consejo de Departamento de Patrimonio Histórico Artístico y de la Cultura Escrita, vino a designar un Consejo de Redacción, formado por los doctores Campos Sánchez-Bordona, Galván Freile, García Álvarez, Hernando Carrasco, Morais Vallejo, Tejeira Pablos y Valdés Fernández, con el mandato de, primero, poner en funcionamiento una revista de carácter científico que difunda trabajos de investigación sobre historia del arte; segundo, arbitrar un sistema que garantizase la valía científica de los trabajos; tercero, determinar el formato; cuarto, definir el ámbito de los investigadores; $y$, en quinto lugar, proponer al Consejo de Departamento el nombre de la revista y designar al secretario y al director.

Los acuerdos tomados por el Consejo de Redacción fueron los siguientes: 1), fue definida la revista como un órgano de difusión de los trabajos de investigación sobre historia del arte elaborados por investigadores españoles y extranjeros, vinculados a los departamentos universitarios, institutos de investigación, organismos oficiales y museos; 2), saldrá bajo el epígrafe $D E$ ARTE. Revista de Historia del Arte de la Facultad de Filosofía y Letras. Universidad de León, con una periodicidad anual; 3), el aval científico de los artículos vendrá determinado por los informes de Consejo de Redacción y, en segunda instancia, por el Comité Científico, formado por los doctores I. G. Bango Torviso de la Universidad Autónoma de Madrid, D. Kimpel de la Universidad de Stuttgart, M. M. Lozano Bartolozzi de la Universidad de Extremadura, D. Martens, de la Universidad Libre de Bruselas, y A. J. Morales de la Universidad de Sevilla, a los que les expresamos nuestro agradecimiento; 4), especificó un conjunto de normas para el envío de los originales; 5), enumeró las obligaciones del Consejo de Redacción para con los colaboradores; y 6), designó, respectivamente, a Fernando Galván Freile y a Manuel Valdés Fernández como Secretario y Director de la revista DE ARTE. 